\title{
A time for everything and everything in its time - exploring the mechanisms underlying seasonality of COPD exacerbations
}

This article was published in the following Dove Press journal: International Journal of COPD

\author{
Alexander Hicks ${ }^{1-3}$ \\ Eugene Healy' \\ Natasha Sandeman' \\ Martin Feelisch ${ }^{1,2}$ \\ Tom Wilkinson ${ }^{1-4}$ \\ 'Clinical and Experimental Sciences, \\ University of Southampton - \\ Faculty of Medicine, Southampton \\ General Hospital, Southampton, UK; \\ ${ }^{2}$ Southampton NIHR Respiratory \\ Biomedical Research Centre, \\ Southampton General Hospital, \\ Southampton, UK; ${ }^{3}$ National Institute \\ for Health Research Collaboration \\ for Leadership in Applied Health \\ Research and Care (NIHR CLAHRC) \\ Wessex, Southampton General \\ Hospital, Southampton, UK; ${ }^{4}$ Wessex \\ Investigational Sciences Hub, \\ University of Southampton - Faculty \\ of Medicine, Southampton General \\ Hospital, Southampton, UK
}

\begin{abstract}
Across Europe, COPD affects 23 million people leading to annual health care costs of $\sim € 25.1$ billion. This burden is particularly severe during winter months in association with the peak incidence of exacerbation events. Seasonal variation in the health status of patients with COPD places additional and often critical pressure on already strained health care resources. COPD exacerbations are characterized by worsening day-to-day symptoms of an individual and often triggered by respiratory infections, but the process by which this occurs in a seasonal fashion is likely to be multifactorial. In this review, we discuss recent population studies that highlight the impact of seasonality in COPD and review the proposed biological mechanisms underlying this. An appraisal of the role of the host susceptibility and response, environmental triggers and the biology of respiratory pathogens is detailed. The impact of each aspect is considered, and an integrated model of the context for the whole individual and society in general is explored.
\end{abstract}

Keywords: COPD exacerbation, seasonality, pollution, weather

\section{Introduction}

Life on earth is intimately linked to the level of energy (ultraviolet [UV], visible, and infrared radiation) received from the sun, and the variations in the angle of earth's rotational axis on its elliptic course gives rise to various seasons. Seasonality affects all forms of life as they adapt to overcome the environmental challenges associated with this cycle. ${ }^{1}$ Variations in the mammalian reproductive cycle are among the best documented biological phenomena studied in relation to seasonality, with the level of fertility changing at certain times of the year to improve the chances of survival of offspring. ${ }^{2}$ However, there is evidence that many other physiological functions and human disease-related conditions exhibit similar seasonal and also circadian patterns, for example, cardiovascular, ${ }^{3}$ physiological state, ${ }^{4}$ autoimmune, ${ }^{5}$ cutaneous, ${ }^{6,7}$ and psychiatric disorders. $^{8}$

The association of COPD with seasonality is notable. ${ }^{9,10}$ Individuals with COPD recognize that they are more likely to experience exacerbations in winter, with $30 \%$ of COPD patients being frightened of this season..$^{11}$ Indeed, some of the more affluent patients with chronic conditions such as COPD and rheumatoid arthritis holiday in sunnier climates during winter, a fact evidenced by the presence of websites encouraging extended winter holidays for this population. ${ }^{12}$ This perceived risk is supported by evidence from clinical studies ${ }^{9,10}$ demonstrating an increased incidence of COPD exacerbations in the winter months in temperate climates, but not in warmer
Correspondence: Alexander Hicks Room LFI3a, South Academic Block, Southampton University Hospital, Tremona Rd, Southampton SOI6 6YD, UK

Tel +44238I 206397

Email a.p.hicks@soton.ac.uk 
tropical environments. The underlying mechanisms for this variance are not clear, suggesting a variety of factors including host biology, environmental conditions, and pathogen alteration.

In this review, we set out to identify our current understanding of the factors that influence COPD exacerbation seasonality and suggest avenues where further research may reduce risk and improve outcomes.

\section{Importance of seasonality in COPD exacerbation rates}

The GOLD guide defines a COPD exacerbation as an acute event characterized by the worsening of a patient's respiratory symptoms that is beyond normal day-to-day variation and leads to a change in medication. ${ }^{13}$ However, COPD exacerbations are not always easily demarcated due to the heterogeneity of factors precipitating the event, the variation in the patient's perception of an exacerbation, and biological response to the precipitating factor(s) in terms of severity and duration of symptoms. This leads to differences in the criteria used by studies to define both the disease itself and the presence of an exacerbation.

Allowing for this variation, a systematic search, on the PubMed and Embase libraries, using the search terms of "seasonality" and "COPD exacerbations" identified seven separate studies showing a seasonal variation in COPD exacerbations..$^{9,10,14-19}$ A large international multicenter study, the TORCH trial, has shown that seasonality in temperate climates increases the rate of exacerbations, with an almost twofold increase in winter compared with summer months. ${ }^{9}$ This is further supported by extrapolation of results from the POET-COPD study which documented a 116\% increase in exacerbation rates from December to February when compared with June to August in a study of 7,376 patients over 12 months. ${ }^{19}$ Recent data from the SPIROMICS cohort study additionally challenged the concept that individuals can be categorized as either frequent or infrequent exacerbators. Over a 3-year period, many individuals varied on an annual basis in their exacerbation events, suggesting that external influences are important in an individual's risk of exacerbation..$^{20,21}$

This seasonal variation in exacerbation incidence has a corresponding effect on hospital admissions in many different health care systems ${ }^{22-24}$ and is also associated with an increase in mortality. ${ }^{25}$ Therefore, a greater understanding of the factors that contribute to these seasonal increases in exacerbation rates should provide opportunities to protect patients and reduce the burden on already overstretched health care systems.

\section{Host physiology}

The immune system plays a key role in infectious exacerbations of patients with COPD. How seasonality affects this process is complex and multifactorial.

\section{Seasonal effects on gene expression and cytokine pattern - length of day}

Dopico et al have highlighted that seasonality affects the expression of genes such as $A R N T L$, which is known to be associated with the immune response. ${ }^{1}$ This study used cohorts of patients recruited for studies with a variety of longterm conditions including asthma and type 1 diabetes. ${ }^{26,27}$ The authors were able to show that the expression of anti-inflammatory genes was altered by the time of year. Importantly, those more highly expressed in June, July, and August in the northern hemisphere were seen to be raised in December, January, and February (corresponding to the equivalent day lengths and climatic conditions) in the southern hemisphere. This difference was also reflected by the presence of circulating immune cells, which were increased during the winter period in the UK. In equatorial climates where day length and temperature were less variable, there was still evidence of seasonal immune variation linked to rainfall, reflecting the period with the highest incidence of infection.

This relationship may deliver an evolutionary advantage by priming the immune system during the highest risk period for infection. However, other smaller studies have suggested reduced cell-mediated immunity and T-cell function during winter and/or periods spent in colder climates, ${ }^{28,29}$ and the overall effects of the winter season on cutaneous and/or systemic immune function may result from a combination of individual effects due to alterations in the length of daytime, exposure of skin to sunshine, body/skin temperature, and hormonal changes. Animal studies support a role for photoperiodic variation in the immunological response. ${ }^{30}$ Changes are controlled by the hypothalamic suprachiasmatic nucleus which responds to light via the nocturnal pineal melatonin rhythm (MEL); as day length alters throughout the year, the MEL signal changes in a predictable and reproducible way, resulting in higher levels of melatonin during winter. Melatonin blocks differentiation of Th17 cells (resulting in less interleukin [IL]-17A expression) and induces the production of Treg1 cells (with a consequential increase in IL-10 production $^{31}$ ), thus permitting an exacerbation. The change in circulating immune cells in these cohort studies ${ }^{1,26,27}$ has previously been reproduced in studies of rodents maintained under artificial light conditions mimicking short and long days. In vivo studies in Siberian hamsters demonstrated that the inflammatory response to a bacterial challenge or wound 
healing partially varied with the time of year in which the challenge took place. The prevailing cytokine profile also varies in these rodents leading to a change in strength of their immune response. ${ }^{30}$ Specifically, circulating levels of IL-1 $\beta$, IL-6, and tumor necrosis factor $\alpha$ were reduced following lipopolysaccharide challenge in animals under short day conditions. ${ }^{32,33}$ Equivalent responses in COPD patients may result in greater risk of exacerbation in short winter days as early local immune defenses would be impaired. ${ }^{34}$

\section{The role of hormonal effects}

Animal models highlight the role for hormonal changes in photoperiodicity and immune function, which could alter the susceptibility to COPD exacerbations. In particular, thyroid, pituitary, and gonadal hormones have been implicated in the response to photoperiodicity. ${ }^{30}$

Gonadal hormones have been investigated to determine whether there is a seasonal variation in their impact on immunity, given their established influence on reproductive cycles as a result of day length. ${ }^{30}$ These studies have shown conflicting responses. Castration was shown to cause a rise in levels of CD3+T-lymphocyte numbers that were similar, although less profound, to the effect seen in male Siberian hamsters maintained in short daylight conditions. ${ }^{35}$ However, the practical benefit of gonadal hormones in the skin inflammatory response associated with photoperiodicity via lymphocyte proliferation has not been confirmed as testosterone supplementation failed to alter the effect of day length. ${ }^{36}$

Seasonal variations in thyroid hormones have also been demonstrated to alter the reproductive cycle. ${ }^{37-39}$ The active component, triiodothyronine $\left(\mathrm{T}_{3}\right)$, has been established as a key regulator of many different processes in the immune system. ${ }^{40,41}$ The effect of photoperiodicity on the role of thyroid hormones was investigated in animal models via its influence on DIO3 mRNA, DNMT3B mRNA, and DIO3 promotor methylation in different tissue types. ${ }^{30,42-44}$ This showed that day length does alter the synthesis of $\mathrm{T}_{3}$ in different tissue types.

Such changes in immune function in response to seasonal hormone variations have so far only been studied in animal models. Prospective studies of the impact of seasonal variations in thyroid levels on the risk of infectious exacerbations in COPD are warranted since they may contribute to the increased exacerbation rates seen in the winter.

\section{Effects of variation in day length}

Photoperiodicity is not the sole controlling mechanism for seasonality in the immune system as Dopico et al showed that there was an equivalent rise in white cell numbers during the wet season in equatorial climates. ${ }^{1}$ These wet periods are associated with the highest rates of parasitic infections. Thus, while there is no change in day length or significant temperature alterations in the tropics, there is still an advantage of seasonal variability in certain biological responses, supporting the concept of a seasonal change in immunity. ${ }^{45}$

Intriguingly, data showed that there was a reduction in the equivalent seasonal variation in an Icelandic cohort of patients. ${ }^{1}$ An explanation for this may be the requirement of the MEL rhythm to have a period of downregulation to be effective, as seen in rodents. ${ }^{30}$ The extreme latitude of Iceland leads to almost 24-hour daylight in the summer, thereby losing the time for downregulation. These findings suggest a greater complexity in control of the immune response to seasonality than it being a simple reflection of the photoperiod.

\section{Environmental factors Temperature}

In the general population, extremes in temperature are associated with an increase in morbidity and mortality. ${ }^{46}$ This effect is also seen in the respiratory disease setting; for example, in 48 patients with COPD, there was an association with patientreported quality-of-life scores and hours of warmth. ${ }^{47}$ There is a complex interaction between lower temperatures seen in the winter and the increase in mortality rate observed. In the UK population, the average temperature for the preceding 13 days has been shown to be associated with national mortality rates, particularly in those with preexisting lung disease. ${ }^{48}$ The influence of cold weather on respiratory complaints is supported by a study from China showing increased health care attendance during periods of lower temperatures. ${ }^{49}$ This is not a simple linear response to cold weather since countries with warmer average temperatures have an even greater increase in mortality with a comparable fall in temperature. ${ }^{50}$ An explanation for this may be that in colder climates there is better adaption in terms of both quality of housing and personal clothing to cope with those changes. ${ }^{25}$ This explanation is supported by the findings of a study of children with asthma, where housing improvements led to a reduction in asthma symptoms. ${ }^{51}$ Deprivation has also been shown to have impact on COPD exacerbation rates in the winter. A Scottish study implied that access to warm clothing and housing altered a patient's risk of exacerbating. ${ }^{52}$ Despite these findings, a systematic review of European studies did not support the suggestion that housing changes can reduce mortality from respiratory disease. ${ }^{53}$ 
These inconsistencies related to the impact of cold, environment, and season on respiratory disease, in particular in patients with COPD, are likely a reflection of the complexity of the interplay between a variety of environmental factors and the infectious agent itself and the immune response elicited by the host. Wanka et al have highlighted this by showing that meteorological factors had a significant but nonlinear overlap with pollution findings that made predicting morbidity in asthma or COPD patients difficult. ${ }^{54}$

\section{Precipitation and humidity}

The impact of climatic conditions is not solely due to temperature differences. In subtropical climates, the seasonal variation in infection rates remains although there is minimal temperature variation throughout the year. Instead, rates of infection in general, and respiratory viral infections in particular, follow the progress of wet seasons ${ }^{55}$ Where the average precipitation rate was $>150 \mathrm{~mm}$ per month, there was a rise in seasonal influenza activity, although the effect is less pronounced and reliable than that seen with changes in temperature in temperate climates. ${ }^{56}$

The effects of humidity on exacerbation rates may be linked via viral transmission, with lower humidity levels leading to increased transmission rates ${ }^{55-57}$ Relative humidity $(\mathrm{RH})$ is the water content in a gas mixture, such as the air we breathe, relative to the ability of the gas to hold the water at a given temperature. It is influenced by ambient temperature, which could therefore be the ultimate determinant of infection and associated exacerbations. However, animal models using influenza infection show that where temperature is controlled for, ambient humidity levels alone are sufficient to alter the rate of infection. ${ }^{58}$ Rather than $\mathrm{RH}$, absolute humidity (AH), which measures water content regardless of temperature, has been shown to more accurately model viral infection rates in temperate climates. ${ }^{59}$

The relationship between humidity and viral infection rate is not linear. Instead, a rise in infection occurs at low temperatures in association with a low $\mathrm{AH}$, whereas at higher temperatures the reverse is seen. ${ }^{60}$ This reflects underlying viral biology with low AH limiting viral envelope disruption at low temperatures. At higher temperatures, the virus is at risk of desiccation, accounting for a protective effect of higher AH. A crossover point therefore exists at which the positive and negative effects of $\mathrm{AH}$ are neutral. Based on the global infection rates, this is suggested to be at $24^{\circ} \mathrm{C}$, but confirmatory laboratory data are limited with only temperatures $<20^{\circ} \mathrm{C}$ been studied. ${ }^{60}$

\section{Interactions between pollution and seasonal effects}

The significance of air pollution on seasonality in COPD exacerbations is integrally linked to weather and temperature. The effects of air pollution are a significant public health concern, with increasing governmental focus on control in both the developing and developed world. ${ }^{61,62}$ Airway damage has been shown to occur in children, ${ }^{63}$ but eliciting a causative effect for COPD is more difficult. The effect of living closer to high pollution sites did influence disease rates of women in Germany, ${ }^{64,65}$ but was not reproduced in an adult population in the UK. ${ }^{66}$

The relationship between air pollution and acute exacerbations of COPD is more established. Large population studies in both European and American cities have shown rises in admission rates and symptomatology in association with increased pollution levels. ${ }^{67-69}$ Interestingly, equivalent effects are also seen in more rural locations when pollution levels rise from a low baseline indicating a dose-dependent response regardless of the background concentration of pollutants. ${ }^{70}$

Pertinent to this review, the impact of pollution on mortality is also subject to seasonal variation. ${ }^{71}$ National governments have identified significant issues with air quality as a result of pollution in recent years. ${ }^{72} \mathrm{~A}$ large multicenter study in China has shown that there is an association with season, particulate matter (PM), and mortality that follows a biannual pattern, with peaks in mortality in summer and winter. ${ }^{72}$ The study reviewed data from 17 large cities to model for any changes seen following a rise in PM by $>10 \mu \mathrm{g} / \mathrm{m}^{3}$. The greater increases seen in summer as well as winter months may reflect the predominant use of coal-fired power stations for energy generation in China which are required for both winter heating and summer cooling in homes and industries. Curiously, and in contrast with COPD-specific study data where seasonal exacerbation rates are more marked in temperate climates, the mortality impact was more pronounced the closer to the equator the city was located.

\section{Sunlight}

Heliotherapy has been used as a treatment for centuries. Its practice proved popular; but even one hundred years ago, it was controversial with the first editorial in the British Journal of Tuberculosis being used to question its value. ${ }^{73}$ However, UV has a variety of effects on the skin/body, including synthesis of vitamin $\mathrm{D}$, and thus effects on tuberculosis killing by macrophages ${ }^{74}$ and local/systemic immunosuppression. 
The ability of UV radiation to alter the immune response was eventually documented conclusively in the 1970s. Investigating the impact of UV in skin cancer biology led to the understanding that UV radiation reduces the ability of the immune system to suppress tumor development. ${ }^{75,76}$ Further work has shown multiple immune effects from exposure to sunlight leading to reduction in not only local processes such as psoriasis but also systemic conditions including respiratory diseases such as asthma. ${ }^{77}$ The UVB wavelengths (290-315 nm) are considered the key components in sunlight responsible for immune modulation, although a role for UVA has also been suggested. ${ }^{77,78}$ The amount of solar UVB radiation reaching the earth's surface is dependent on the distance that the radiation travels through the ozone layer in the upper atmosphere. This means that, as a result of the rotational angle of the earth in relation to the sun, reduced levels of UVB exposure are seen at higher latitudes during winter months. ${ }^{78,79}$ In addition, cloud cover can attenuate up to $99 \%$ of UVB radiation, thus further impacting on levels during winter months at higher latitudes and in the rainy season in equatorial conditions. ${ }^{80,81}$

UV-induced immunosuppression is not likely to be a key determining factor in COPD exacerbations in relation to influenza or viral exacerbations because there is less UV exposure in winter. However, UV light might be relevant via its inhibitory effect on systemic inflammation during summer but not winter when COPD exacerbation occurs. Therefore, enhanced low-level inflammatory processes, which are also energetically costly to control, may contribute to unfavorable alterations in systemic redox status due to increased oxidative stress. The role of oxidative stress in COPD has recently been reviewed and is beyond the scope of this paper, but a specific role for seasonality in this process has not been studied. ${ }^{82}$

UV exposure has also been linked to viral infection partly through this role in immunosuppression. It is recognized to cause viral reactivation of the herpes simplex virus. ${ }^{83}$ Solar insolation (ie, the amount of solar radiation reaching the earth's surface) has therefore been incorporated in modeling of environmental factors that influence respiratory viral infection rates. However, the decrease in solar insolation seen in winter months was not found to track infection rates. ${ }^{59}$

The role of sunlight and UV radiation in the regulation of immune system activity has been intrinsically linked to its actions on vitamin D synthesis. ${ }^{84}$ While seasonal variation in serum vitamin D levels relates to UV exposure during summer months, a systematic review has highlighted that adequate vitamin D levels are maintained in winter in over $50 \%$ of individuals. ${ }^{6}$ The role of UVB radiation in this context is to aid the conversion of pro-vitamin D3 (7-dehydrocholesterol) to pre-vitamin D3 (pre-cholecalciferol) before further steps in the liver and kidney convert it to its activated form, 1,25-dihydroxyvitamin D3. However, some of the seasonal deterioration in immune function might be ameliorated by a change in diet. ${ }^{85} \mathrm{~A}$ level of $>50 \mathrm{nmol} / \mathrm{L}$ is seen as adequate, with some authors considering $>75 \mathrm{nmol} / \mathrm{L}$ as optimal for the overall well-being of the individual, ${ }^{6,86}$ but the precise adequate concentration of vitamin $\mathrm{D}$ present in an individual to maintain health is difficult to define and therefore assessing whether seasonal reductions have a clinical effect is challenging.

Vitamin D itself has multiple properties that impact on the immune system. It can drive immune cells such as monocytes, macrophages, and neutrophils to produce antimicrobial peptides including LL-37 and $\beta$-defensin 2, which enhance the bactericidal properties of these cells. ${ }^{87}$ It also drives differentiation of a variety of different immune cells including dendritic cells, T cells, and monocytes to support specific immune responses, placing it in a key position to alter the inflammatory response seen in COPD exacerbations. ${ }^{88-90}$ However, immune cells themselves express the inducible enzyme, CYP27B1 (1 $\alpha$-hydroxylase), so they too can make 1,25-dihydroxyvitamin D3 and cause an autocrine effect at a local level that may alter the immune response independently of sunlight exposure. ${ }^{91}$ Its overall impact though remains less clear with a comprehensive systematic review of vitamin D status and ill health, suggesting that the observed low vitamin $\mathrm{D}$ levels seen in association with higher mortality may reflect frailty rather than a trigger for illness. ${ }^{92}$

Sunlight exposure or vitamin D supplementation has been proposed as potential therapies. In those with steroid resistant asthma ${ }^{93}$ and in those with newly diagnosed disease, ${ }^{94}$ the addition of vitamin $\mathrm{D}$ to the diet has been shown to improve clinical outcomes as well as in infectious conditions such as tuberculosis. ${ }^{87,95}$ A systematic review of asthma exacerbations, including seven separate studies, demonstrated a clinically relevant reduction in steroid use with vitamin D supplementation. ${ }^{96}$ Importantly, in the context of COPD, a large meta-analysis showed that vitamin D supplementation reduced acute respiratory tract infections. ${ }^{97}$ Although this suggests a role for vitamin $\mathrm{D}$ therapy in respiratory conditions in general, other treatment studies have failed to show a clear benefit ${ }^{95,98}$ in line with other diseases. ${ }^{99}$ This may reflect the low thresholds $(<25 \mathrm{nmol} / \mathrm{L})$ used by the positive studies to indicate those individuals requiring treatment. For example, 
in a study of muscle strength in COPD where the treatment and interventions arms had levels $>40 \mathrm{nmol} / \mathrm{L}$, there was no impact from vitamin D supplementation. ${ }^{100}$

In patients with COPD, a reduction in day length has been shown to be associated with a reduction in the presence of 25-hydroxyvitamin D. ${ }^{101}$ However, despite the importance of vitamin $\mathrm{D}$ in immunomodulation in experimental model systems, its use in clinical practice remains controversial. In observational studies, low levels of its activated form, 1,25-dihydroxyvitamin $\mathrm{D}$, did not result in an increased frequency of COPD exacerbations ${ }^{12,101,102}$ or a reduction in the susceptibility to human rhinovirus (HRV) infection. ${ }^{101}$ Subgroup analysis from two separate studies has shown that although infection rates are not altered, the time to exacerbation is increased in those individuals with low vitamin D levels who are given dietary vitamin D supplementation. ${ }^{103,104}$ A systematic search of the online databases Embase, Medline, and the Cochrane Library for vitamin D supplementation and COPD exacerbations identifies two separate studies ${ }^{100,103}$ and two trials in progress. Those trials to report showed a positive response, predominantly in patients with initial low vitamin D levels. The ongoing randomized controlled trial (PRECOVID trial) of vitamin D supplementation in COPD patients may add further evidence for its use. ${ }^{105}$

A confounding factor in any discussion on vitamin D levels and photoperiodicity is the impact of diet. Historic cultural dietary alteration in indigenous populations in Alaska, for example, developed to account for the inability to synthesize the active form in winter months. With a generational move to Western diets, this seasonal dietary supplementation is being lost which may in turn lead to long-term respiratory health effects. ${ }^{106}$ Although seasonal variation in diet in developed countries is relatively limited, ${ }^{107}$ the impact on a subset of other micronutrients such as vitamins $C$ and D has not been consistently shown to be altered. ${ }^{107}$

It has been argued that vitamin D may simply be a biomarker of sunlight exposure and that the beneficial effects of sunlight for cardiovascular and metabolic (and perhaps also respiratory) health are due to the release of additional factors from the skin. ${ }^{108}$ One such factor may be nitric oxide (NO), and it is conceivable that the increase in COPD exacerbations in the northern hemisphere in winter is linked to the nadir in UV-induced NO release during this time of year.

$\mathrm{NO}$ is another immunomodulator induced by UV radiation exposure. ${ }^{77} \mathrm{NO}$ is a ubiquitous messenger and effector molecule that can be formed by two independent enzymatic routes that depend on the availability of either L-arginine (which is a substrate for nitric oxide synthase, NOS) or nitrate (which can be sequentially reduced to nitrite and NO by a variety of enzymatic and non-enzymatic pathways). ${ }^{109}$ In addition, sunlight exposure can liberate NO from preformed storage forms located in the epidermal layer of the skin, ${ }^{110}$ possibly leading to alterations in tissue levels during periods of reduced light exposure. ${ }^{111}$ Exposure to UV light also drives the synthesis and release of $\alpha$-melanocyte stimulating hormone $(\alpha-\mathrm{MSH})$, which in turn acts as an antiinflammatory agent in part by curtailing $\mathrm{NO}$ and peroxynitrite production from inducible NOS. ${ }^{112,113}$ In patients with COPD, measurements of exhaled NO have been used as a surrogate for exacerbations given its importance in the inflammatory process. ${ }^{114}$ It has been shown that exhaled NO levels are raised during winter months, suggesting a degree of active inflammation. ${ }^{115}$ This could reflect inter-current viral infection or additionally represent the impact of low $\alpha$-MSH in response to low UV levels as there are no specific trials looking at this response.

\section{Pathogens}

About $50 \%-70 \%$ of COPD exacerbations are triggered by either bacterial or viral infections that stimulate an inflammatory response. ${ }^{116-120}$ Many of these infectious agents have also been found to have a seasonal variation in their infection rates. Certain viruses, including respiratory syncytial virus, HRVs, and influenza A and B, along with bacteria like Mycoplasma pneumoniae have peaks of incidence in the winter months. ${ }^{25}$ The reason for these peaks in infection may relate to both environmental and host factors.

As alluded to earlier, UV radiation, temperature, and humidity have been highlighted as key to viral survival in the environment. For example, the relative proportion of dissolved salts in water droplets has been proposed as a cause for the influence of humidity on infection. Salt levels fall with a drop in humidity as they crystallize out of solution leading to high virion stability. ${ }^{121}$ Infectious agents can also be preserved for longer in the cold, thereby increasing the opportunity for patient exposure, ${ }^{55}$ and finally UV radiation inactivates viruses by chemically modifying their genetic material. ${ }^{122}$ The relative importance of the pathogen versus environmental factors can be seen in a longitudinal study of influenza-related mortality in Chinese cities that covered both temperate and tropical climates. ${ }^{123}$ In this 6-year study, overall death rates and influenza-related fatalities were compared between three northern, temperate cities and five southern, tropical ones. In both the regions, there was a seasonal variation in mortality, but it only corresponded with influenza rates in the cooler northern cities, suggesting that weather and temperature were necessary to 
create seasonal viral variation rather than a property of the pathogen itself. ${ }^{123}$

Many of the host factors that influence exacerbation rates do so by contributing to the ability of the individual to deal with an infectious challenge. Additional factors that relate to respiratory pathogens include the effect of cold on the nasal epithelium, with cooling, reducing blood flow, and impacting on local immune defenses, including phagocytosis ${ }^{124,125}$ and mucocililary clearance. ${ }^{126}$ Adenoviruses and corona viruses have similar infection rates throughout the year, suggesting that there is a difference in the reason for susceptibility to infection depending on the infectious agent. Co-infection may account for some of these. Non-typeable Haemophilus influenzae is known to influence the severity of the inflammatory response and the clinical consequence in patients who are co-infected with viruses such as HRV. ${ }^{119,127}$ It is conceivable, therefore, that many of the seasonal effects we observe in respiratory diseases require the presence of multiple pathogens in the same individual.

Additional research correlating extensive meteorological data including humidity levels and temperature with specific infectious agents in COPD exacerbation might prove helpful in public health strategy. ${ }^{129,130}$ Health care services would be better prepared for outbreaks of certain infections if they were found to have predictable patterns in patients with COPD. HRV infections have recently been shown to rise following a fall in average air temperature over the preceding 3 days, suggesting a marker to predict surges in health care demand. ${ }^{131}$ Public health services do retrospectively monitor for viral infection patterns. Public Health England data from the most recent respiratory virus surveillance in the UK shows that there are yearly seasonal spikes in infection rates that do correspond to winter months. ${ }^{128}$ However, those rates vary on a yearly basis in a manner that does not reflect a linear relationship to temperature alone, highlighting the complex interactions taking place between the individual host, the infectious agent, and the environment.

\section{Conclusion}

Seasonality in COPD exacerbation rates clearly has a major impact on both the individual patient and the wider health care system (summarized in Figure 1). Overall, winter excess mortality rates fell in the UK in the last 20 years before the

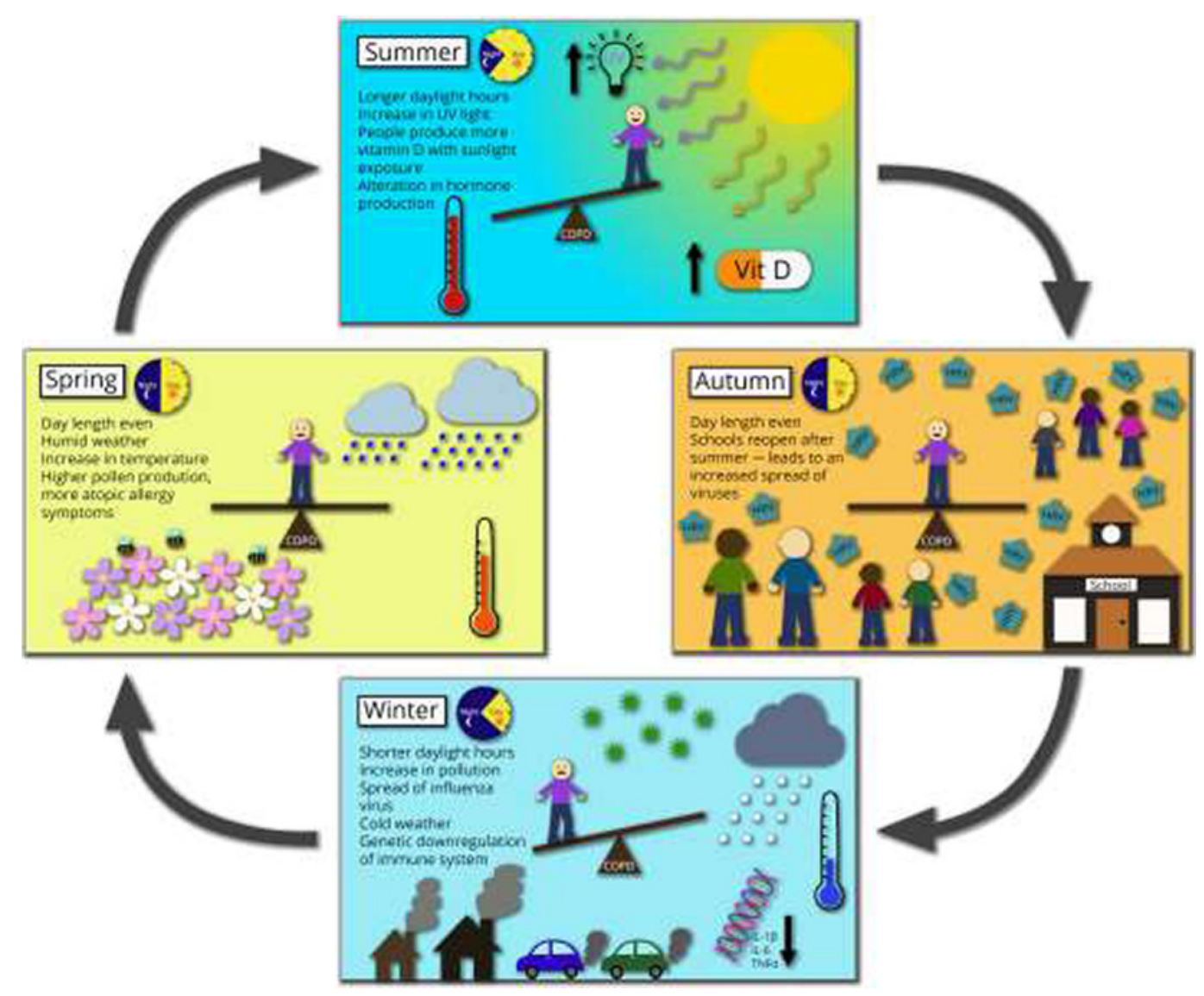

Figure I Abridged pictorial representation of factors contributing to seasonal variations in COPD exacerbations. Abbreviations: UV, ultraviolet; Vit D, vitamin D; IL, interleukin; TNF, tumor necrosis factor. 
millennium. ${ }^{132}$ However, winter pressures in UK hospitals have significantly increased, stimulating the need for models of prediction and prevention. Therefore, a greater understanding of factors influencing COPD exacerbations during the winter could aid long-term planning strategies.

As outlined in this review, seasonal changes are multifactorial and require research that looks at the issue in its entirety. First, the fundamental biology of the patient in response to seasonality needs to be better understood in order to offer prevention and treatment options. With greater comprehension of the mechanistic events that drive seasonal variations, new targets and avenues for therapeutic intervention could be identified.

In addition, research should be undertaken with a clear knowledge of the changing environmental conditions that patients experience. It is interesting to speculate as to how climate change will impact on these external factors, such as temperature, humidity, pollution levels, and local pathogen rates. In this study, we have discussed the factors separately although they are all clearly interconnected; importantly, with growing climate extremes, there is a risk that this will impact on seasonal variations in exacerbations rates. Given that patients cannot be readily relocated to milder climates during winter weather conditions, it is important to understand how all these factors have an impact together and where any interventions can be targeted. Therefore, large multicenter longitudinal studies are required to provide a research context for health care modeling in order to prioritize limited resources and importantly to offer new opportunities to limit risk-associated exposures for this vulnerable and sizeable patient group.

\section{Disclosure}

The authors report no conflicts of interest in this work.

\section{References}

1. Dopico XC, Evangelou M, Ferreira RC, et al. Widespread seasonal gene expression reveals annual differences in human immunity and physiology. Nat Commun. 2015;6:7000.

2. Dowell SF. Seasonal variation in host susceptibility and cycles of certain infectious diseases. Emerg Infect Dis. 2001;7(3):369-374.

3. Pell JP, Cobbe SM. Seasonal variations in coronary heart disease. QJM. 1999;92(12):689-696.

4. Scholtissek B, Zahn S, Maier J, et al. Immunostimulatory endogenous nucleic acids drive the lesional inflammation in cutaneous lupus erythematosus. J Invest Dermatol. 2017;137(7):1484-1492.

5. Iikuni N, Nakajima A, Inoue E, et al. What's in season for rheumatoid arthritis patients? Seasonal fluctuations in disease activity. Rheumatology (Oxford). 2007;46(5):846-848.

6. Rice SA, Carpenter M, Fityan A, et al. Limited exposure to ambient ultraviolet radiation and 25-hydroxyvitamin D levels: a systematic review. Br J Dermatol. 2015;172(3):652-661.
7. Yoneshiro T, Matsushita M, Nakae S, et al. Brown adipose tissue is involved in the seasonal variation of cold-induced thermogenesis in humans. Am J Physiol Regul Integr Comp Physiol. 2016 Epub Mar 30.

8. Owens N, McGorry PD. Seasonality of symptom onset in first-episode schizophrenia. Psychol Med. 2003;33(1):163-167.

9. Jenkins CR, Celli B, Anderson JA, et al. Seasonality and determinants of moderate and severe COPD exacerbations in the TORCH study. Eur Respir J. 2012;39(1):38-45.

10. Williams NP, Coombs NA, Johnson MJ, et al. Seasonality, risk factors and burden of community-acquired pneumonia in COPD patients: a population database study using linked health care records. Int $J$ Chron Obstruct Pulmon Dis. 2017;12:313-322.

11. Miravitlles M, Anzueto A, Legnani D, Forstmeier L, Fargel M. Patient's perception of exacerbations of COPD - the PERCEIVE study. Respir Med. 2007;101(3):453-460.

12. Puhan MA, Siebeling L, Frei A, Zoller M, Bischoff-Ferrari H, Ter Riet G. No association of 25-hydroxyvitamin D with exacerbations in primary care patients with COPD. Chest. 2014;145(1):37-43.

13. Global Initiative for Chronic Obstructive Lung Disease. Pocket Guide to COPD Diagnosis, Management, and Prevention. A Guide for Health Care Professionals. 2017 ed. 2016. Available from: https://goldcopd. org/wp-content/uploads/2016/12/wms-GOLD-2017-Pocket-Guide.pdf. Accessed March 19, 2018.

14. Wise RA, Calverley PMA, Carter K, Clerisme-Beaty E, Metzdorf N, Anzueto A. Seasonal variations in exacerbations and deaths in patients with COPD during the TIOSPIR((R)) trial. Int J Chron Obstruct Pulmon Dis. 2018;13:605-616.

15. McCarthy H, Jackson M, Corcoran M, et al. Colonisation of Irish patients with chronic obstructive pulmonary disease by Streptococcus pneumoniae and analysis of the pneumococcal vaccine coverage: a non-interventional, observational, prospective cohort study. BMJ Open. 2017;7(7):e013944.

16. Wilkinson TMA, Aris E, Bourne $\mathrm{S}$, et al. A prospective, observational cohort study of the seasonal dynamics of airway pathogens in the aetiology of exacerbations in COPD. Thorax. 2017;72(10):919-927.

17. Brzezinska-Pawlowska OE, Rydzewska AD, Łuczyńska M, MajkowskaWojciechowska B, Kowalski ML, Makowska JS. Environmental factors affecting seasonality of ambulance emergency service visits for exacerbations of asthma and COPD. J Asthma. 2016;53(2):139-145.

18. Almagro P, Hernandez C, Martinez-Cambor P, Tresserras R, Escarrabill J. Seasonality, ambient temperatures and hospitalizations for acute exacerbation of COPD: a population-based study in a metropolitan area. Int J Chron Obstruct Pulmon Dis. 2015;10:899-908.

19. Rabe KF, Fabbri LM, Vogelmeier C, et al. Seasonal distribution of COPD exacerbations in the Prevention of Exacerbations with Tiotropium in COPD trial. Chest. 2013;143(3):711-719.

20. Han MK, Quibrera PM, Carretta EE, et al. Frequency of exacerbations in patients with chronic obstructive pulmonary disease: an analysis of the SPIROMICS cohort. Lancet Respir Med. 2017;5(8):619-626.

21. Hurst JR, Anzueto A, Vestbo J. Susceptibility to exacerbation in COPD. Lancet Respir Med. 2017;5(9):e29.

22. Vilkman S, Keistinen T, Tuuponen T, Kivelä SL. Seasonal variation in hospital admissions for chronic obstructive pulmonary disease in Finland. Arctic Med Res. 1996;55(4):182-186.

23. Brims FJ, Asiimwe A, Andrews NP, et al. Weekend admission and mortality from acute exacerbations of chronic obstructive pulmonary disease in winter. Clin Med. 2011;11(4):334-339.

24. Mapel DW, Dedrick D, Davis K. Trends and cardiovascular co-morbidities of COPD patients in the Veterans Administration Medical System. 1991-1999. COPD. 2005;2(1):35-41.

25. Donaldson GC, Wedzicha JA. The causes and consequences of seasonal variation in COPD exacerbations. Int J Chron Obstruct Pulmon Dis. 2014;9:1101-1110.

26. Beyerlein A, Wehweck F, Ziegler AG, Pflueger M. Respiratory infections in early life and the development of islet autoimmunity in children at increased type 1 diabetes risk: evidence from the BABYDIET study. JAMA Pediatr. 2013;167(9):800-807. 
27. Bjornsdottir US, Holgate ST, Reddy PS, et al. Pathways activated during human asthma exacerbation as revealed by gene expression patterns in blood. PLoS One. 2011;6(7):e21902.

28. MacMurray JP, Barker JP, Armstrong JD, Bozzetti LP, Kuhn IN. Circannual changes in immune function. Life Sci. 1983;32(20):2363-2370.

29. Muller HK, Lugg DJ, Quinn D. Cell mediated immunity in Antarctic wintering personnel; 1984-1992. Immunol Cell Biol. 1995;73(4): 316-320.

30. Stevenson TJ, Prendergast BJ. Photoperiodic time measurement and seasonal immunological plasticity. Front Neuroendocrinol. 2015; 37:76-88.

31. Farez MF, Mascanfroni ID, Méndez-Huergo SP, et al. Melatonin contributes to the seasonality of multiple sclerosis relapses. Cell. 2015;162(6) 1338-1352.

32. Bilbo SD, Drazen DL, Quan N, He L, Nelson RJ. Short day lengths attenuate the symptoms of infection in Siberian hamsters. Proc Biol Sci. 2002;269(1490):447-454.

33. Prendergast BJ, Hotchkiss AK, Bilbo SD, Kinsey SG, Nelson RJ. Photoperiodic adjustments in immune function protect Siberian hamsters from lethal endotoxemia. J Biol Rhythms. 2003;18(1):51-62.

34. Iwasaki A, Foxman EF, Molony RD. Early local immune defences in the respiratory tract. Nat Rev Immunol. 2017;17(1):7-20.

35. Prendergast BJ, Baillie SR, Dhabhar FS. Gonadal hormone-dependent and -independent regulation of immune function by photoperiod in Siberian hamsters. Am J Physiol Regul Integr Comp Physiol. 2008; 294(2):R384-R392.

36. Prendergast BJ, Bilbo SD, Nelson RJ. Short day lengths enhance skin immune responses in gonadectomised Siberian hamsters. J Neuroendocrinol. 2005;17(1):18-21.

37. Yoshimura T, Yasuo S, Watanabe M, et al. Light-induced hormone conversion of T4 to T3 regulates photoperiodic response of gonads in birds. Nature. 2003;426(6963):178-181

38. Thapliyal JP, Pandha SK. Thyroid-gonad relationship in spotted munia, uroloncha punctulata. J Exp Zool. 1965;158:253-261

39. Yoshimura T. Thyroid hormone and seasonal regulation of reproduction. Front Neuroendocrinol. 2013;34(3):157-166.

40. Chatterjee S, Chandel AS. Immunomodulatory role of thyroid hormones: in vivo effect of thyroid hormones on the blastogenic response of lymphoid tissues. Acta Endocrinol (Copenh). 1983;103(1):95-100.

41. Mascanfroni I, Montesinos Mdel M, Susperreguy S, et al. Control of dendritic cell maturation and function by triiodothyronine. FASEB J. 2008;22(4):1032-1042.

42. Stevenson TJ, Onishi KG, Bradley SP, Prendergast BJ. Cell-autonomous iodothyronine deiodinase expression mediates seasonal plasticity in immune function. Brain Behav Immun. 2014;36:61-70.

43. Barrett P, Ebling FJ, Schuhler S, et al. Hypothalamic thyroid hormone catabolism acts as a gatekeeper for the seasonal control of body weight and reproduction. Endocrinology. 2007;148(8):3608-3617.

44. Watanabe T, Yamamura T, Watanabe M, et al. Hypothalamic expression of thyroid hormone-activating and -inactivating enzyme genes in relation to photorefractoriness in birds and mammals. Am J Physiol Regul Integr Comp Physiol. 2007;292(1):R568-R572.

45. Nelson RJ. Seasonal immune function and sickness responses. Trends Immunol. 2004;25(4):187-192.

46. Conlon KC, Rajkovich NB, White-Newsome JL, Larsen L, Neilla MSO Preventing cold-related morbidity and mortality in a changing climate. Maturitas. 2011;69(3):197-202.

47. Osman LM, Ayres JG, Garden C, Reglitz K, Lyon J, Douglas JG. Home warmth and health status of COPD patients. Eur J Public Health. 2008;18(4):399-405.

48. Wilkinson P, Pattenden S, Armstrong B, et al. Vulnerability to winter mortality in elderly people in Britain: population based study. BMJ. 2004;329(7467):647.

49. Huang F, Zhao A, Chen RJ, Kan HD, Kuang XY. Ambient temperature and outpatient visits for acute exacerbation of chronic bronchitis in Shanghai: a time series analysis. Biomed Environ Sci. 2015;28(1): 76-79.
50. The Eurowinter Group. Cold exposure and winter mortality from ischaemic heart disease, cerebrovascular disease, respiratory disease, and all causes in warm and cold regions of Europe. Lancet. 1997;349(9062): 1341-1346.

51. Howden-Chapman P, Pierse N, Nicholls S, et al. Effects of improved home heating on asthma in community dwelling children: randomised controlled trial. BMJ. 2008;337:a1411.

52. McAllister DA, Morling JR, Fischbacher CM, MacNee W, Wild SH. Socioeconomic deprivation increases the effect of winter on admissions to hospital with COPD: retrospective analysis of 10 years of national hospitalisation data. Prim Care Respir J. 2013;22(3):296-299.

53. Thomson H, Petticrew M, Morrison D. Health effects of housing improvement: systematic review of intervention studies. BMJ. 2001; 323(7306):187-190

54. Wanka ER, Bayerstadler A, Heumann C, Nowak D, Jörres RA, Fischer R. Weather and air pollutants have an impact on patients with respiratory diseases and breathing difficulties in Munich, Germany. Int J Biometeorol. 2014;58(2):249-262.

55. Lowen AC, Steel J. Roles of humidity and temperature in shaping influenza seasonality. J Virol. 2014;88(14):7692-7695.

56. Tamerius JD, Shaman J, Alonso WJ, et al. Environmental predictors of seasonal influenza epidemics across temperate and tropical climates. PLoS Pathog. 2013;9(3):e1003194.

57. Shaman J, Kohn M. Absolute humidity modulates influenza survival, transmission, and seasonality. Proc Natl Acad Sci U S A. 2009;106(9): 3243-3248.

58. Lowen AC, Mubareeka S, Steel J, Palese P. Influenza virus transmission is dependent on relative humidity and temperature. PLoS Pathog. 2007;3(10):1470-1476.

59. Shaman J, Pitzer VE, Viboud C, Grenfell BT, Lipsitch M. Absolute humidity and the seasonal onset of influenza in the continental United States. PLoS Biol. 2010;8(2):e1000316.

60. Deyle ER, Maher MC, Hernandez RD, Basu S, Sugihara G. Global environmental drivers of influenza. Proc Natl Acad Sci U S A. 2016;113(46):13081-13086.

61. Pruss-Ustun A, Wolf J, Corvalán C, Neville T, Bos R, Neira M. Diseases due to unhealthy environments: an updated estimate of the global burden of disease attributable to environmental determinants of health. J Public Health (Oxf). 2017;39(3):464-475.

62. Ko FW, Hui DS. Air pollution and chronic obstructive pulmonary disease. Respirology. 2012;17(3):395-401.

63. Gauderman WJ, Avol E, Gilliland F, et al. The effect of air pollution on lung development from 10 to 18 years of age. $N$ Engl J Med. 2004; 351(11):1057-1067.

64. Schikowski T, Sugiri D, Ranft U, et al. Long-term air pollution exposure and living close to busy roads are associated with COPD in women. Respir Res. 2005;6:152.

65. Schikowski T, Ranft U, Sugiri D, et al. Decline in air pollution and change in prevalence in respiratory symptoms and chronic obstructive pulmonary disease in elderly women. Respir Res. 2010;11:113.

66. Pujades-Rodriguez M, McKeever T, Lewis S, Whyatt D, Britton J, Venn A. Effect of traffic pollution on respiratory and allergic disease in adults: cross-sectional and longitudinal analyses. BMC Pulm Med. 2009;9:42.

67. Anderson HR, Spix C, Medina S, et al. Air pollution and daily admissions for chronic obstructive pulmonary disease in 6 European cities: results from the APHEA project. Eur Respir J. 1997;10(5): 1064-1071.

68. Zanobetti A, Schwartz J, Dockery DW. Airborne particles are a risk factor for hospital admissions for heart and lung disease. Environ Health Perspect. 2000;108(11):1071-1077.

69. Dominici F, Peng RD, Bell ML, et al. Fine particulate air pollution and hospital admission for cardiovascular and respiratory diseases. JAMA. 2006;295(10):1127-1134

70. Sauerzapf V, Jones AP, Cross J. Environmental factors and hospitalisation for chronic obstructive pulmonary disease in a rural county of England. J Epidemiol Community Health. 2009;63(4):324-328. 
71. Peng RD, Dominici F, Pastor-Barriuso R, Zeger SL, Samet JM. Seasonal analyses of air pollution and mortality in 100 US cities. Am J Epidemiol. 2005;161(6):585-594.

72. Chen R, Peng RD, Meng X, Zhou Z, Chen B, Kan H. Seasonal variation in the acute effect of particulate air pollution on mortality in the China Air Pollution and Health Effects Study (CAPES). Sci Total Environ. 2013;450-451:259-265.

73. Editorial. The Tuberculosis problem. British Journal Tuberculosis. 1907; $1(1): 1-4$.

74. Liu PT, Stenger S, Li H, et al. Toll-like receptor triggering of a vitamin D-mediated human antimicrobial response. Science. 2006; 311(5768):1770-1773.

75. Kripke ML. Antigenicity of murine skin tumors induced by ultraviolet light. J Natl Cancer Inst. 1974;53(5):1333-1336.

76. Kripke ML, Fisher MS. Immunologic parameters of ultraviolet carcinogenesis. J Natl Cancer Inst. 1976;57(1):211-215.

77. Hart PH, Gorman S, Finlay-Jones JJ. Modulation of the immune system by UV radiation: more than just the effects of vitamin D? Nat Rev Immunol. 2011;11(9):584-596.

78. Engelsen $\mathrm{O}$. The relationship between ultraviolet radiation exposure and vitamin D status. Nutrients. 2010;2(5):482-495.

79. Rhodes LE, Webb AR, Fraser HI, et al. Recommended summer sunlight exposure levels can produce sufficient ( $>$ or $=20 \mathrm{ng} \mathrm{ml}(-1)$ ) but not the proposed optimal $(>$ or $=32 \mathrm{ng} \mathrm{ml}(-1)) 25(\mathrm{OH}) \mathrm{D}$ levels at UK latitudes. J Invest Dermatol. 2010;130(5):1411-1418.

80. Estupiñán JG, Raman S, Crescenti GH, Streicher JJ, Barnard WF. Effects of clouds and haze on UV-B radiation. J Geophys Res. 1996;101(D11): 16807-16816.

81. Sabburg J, Wong J. The effects of clouds on enhancing UVB irradiance at the Earth's surface: a one year study. Geophys Res Lett. 2000; 27(20):3337-3340.

82. McGuinness AJ, Sapey E. Oxidative stress in COPD: sources, markers, and potential mechanisms. $J$ Clin Med. 2017;6(2):E21.

83. Norval M. The effect of ultraviolet radiation on human viral infections. Photochem Photobiol. 2006;82(6):1495-1504.

84. Holick MF. Evolution and function of vitamin D. Recent results. Cancer Res. 2003;164:3-28.

85. Kokturk N, Baha A, Oh YM, Ju JY, Jones PW. Vitamin D deficiency: what does it mean for chronic obstructive pulmonary disease (COPD)? A comprehensive review for pulmonologists. Clin Respir J. 2016(12):382-397.

86. Roux C, Bischoff-Ferrari HA, Papapoulos SE, de Papp AE, West JA, Bouillon R. New insights into the role of vitamin D and calcium in osteoporosis management: an expert roundtable discussion. Curr Med Res Opin. 2008;24(5):1363-1370.

87. Hewison M. Antibacterial effects of vitamin D. Nat Rev Endocrinol. 2011;7(6):337-345.

88. van der Aar AM, Sibiryak DS, Bakdash G, et al. Vitamin D3 targets epidermal and dermal dendritic cells for induction of distinct regulatory T cells. J Allergy Clin Immunol. 2011;127(6):1532-1540e7.

89. Baeke F, Korf H, Overbergh L, et al. Human T lymphocytes are direct targets of 1,25-dihydroxyvitamin D3 in the immune system. J Steroid Biochem Mol Biol. 2010;121(1-2):221-227.

90. Baeke F, Takiishi T, Korf H, Gysemans C, Mathieu C. Vitamin D: modulator of the immune system. Curr Opin Pharmacol. 2010;10(4): 482-496.

91. Kundu R, Chain BM, Coussens AK, Khoo B, Noursadeghi M. Regulation of CYP27B1 and CYP24A1 hydroxylases limits cell-autonomous activation of vitamin D in dendritic cells. Eur J Immunol. 2014; 44(6):1781-1790.

92. Autier P, Boniol M, Pizot C, Mullie P. Vitamin D status and ill health: a systematic review. Lancet Diabetes Endocrinol. 2014;2(1):76-89.

93. Xystrakis E, Kusumakar S, Boswell S, et al. Reversing the defective induction of IL-10-secreting regulatory $\mathrm{T}$ cells in glucocorticoidresistant asthma patients. J Clin Invest. 2006;116(1):146-155.

94. Majak P, Olszowiec-Chlebna M, Smejda K, Stelmach I. Vitamin D supplementation in children may prevent asthma exacerbation triggered by acute respiratory infection. J Allergy Clin Immunol. 2011; 127(5):1294-1296.
95. Yamshchikov AV, Desai NS, Blumberg HM, Ziegler TR, Tangpricha V. Vitamin D for treatment and prevention of infectious diseases: a systematic review of randomized controlled trials. Endocr Pract. 2009;15(5):438-449.

96. Jolliffe DA, Greenberg L, Hooper RL, et al. Vitamin D supplementation to prevent asthma exacerbations: a systematic review and metaanalysis of individual participant data. Lancet Respir Med. 2017; 5(11):881-890.

97. Martineau AR, Jolliffe DA, Greenberg L, et al. Vitamin D supplementation to prevent acute respiratory tract infections: systematic review and meta-analysis of individual participant data. BMJ. 2017;356: i6583.

98. Martineau AR, Timms PM, Bothamley GH, et al. High-dose vitamin $\mathrm{D}$ (3) during intensive-phase antimicrobial treatment of pulmonary tuberculosis: a double-blind randomised controlled trial. Lancet. 2011;377(9761):242-250.

99. Autier P, Boniol M, Pizot C, Mullie P. Vitamin D status and ill healthauthor's reply. Lancet Diabetes Endocrinol. 2014;2(4):275-276.

100. Rafiq R, Prins HJ, Boersma WG, et al. Effects of daily vitamin D supplementation on respiratory muscle strength and physical performance in vitamin D-deficient COPD patients: a pilot trial. Int JChron Obstruct Pulmon Dis. 2017;12:2583-2592.

101. Quint JK, Donaldson GC, Wassef N, Hurst JR, Thomas M, Wedzicha JA. 25-Hydroxyvitamin D deficiency, exacerbation frequency and human rhinovirus exacerbations in chronic obstructive pulmonary disease. BMC Pulm Med. 2012;12:28.

102. Kunisaki KM, Niewoehner DE, Connett JE; COPD Clinical Research Network. Vitamin D levels and risk of acute exacerbations of chronic obstructive pulmonary disease: a prospective cohort study. Am J Respir Crit Care Med. 2012;185(3):286-290.

103. Martineau AR, James WY, Hooper RL, et al. Vitamin D3 supplementation in patients with chronic obstructive pulmonary disease (ViDiCO): a multicentre, double-blind, randomised controlled trial. Lancet Respir Med. 2015;3(2):120-130.

104. Lehouck A, Mathieu C, Carremans C, et al. High doses of vitamin D to reduce exacerbations in chronic obstructive pulmonary disease: a randomized trial. Ann Intern Med. 2012;156(2):105-114.

105. Rafiq R, Aleva FE, Schrumpf JA, et al. Prevention of exacerbations in patients with COPD and vitamin D deficiency through vitamin D supplementation (PRECOVID): a study protocol. BMC Pulm Med. 2015;15:106.

106. Fohner AE, Wang Z, Yracheta J, et al. Genetics, diet, and season are associated with serum 25-hydroxycholecalciferol concentration in a Yup'ik study population from Southwestern Alaska. J Nutr. 2016; 146(2):318-325.

107. Bernstein S, Zambell K, Amar MJ, et al. Dietary intake patterns are consistent across seasons in a cohort of healthy adults in a metropolitan population. J Acad Nutr Diet. 2016;116(1):38-45.

108. Feelisch M, Gorman S, Weller RB. Vitamin D status and ill health. Lancet Diabetes Endocrinol. 2014;2(4):e8.

109. Lundberg JO, Weitzberg E, Gladwin MT. The nitrate-nitrite-nitric oxide pathway in physiology and therapeutics. Nat Rev Drug Discov. 2008;7(2):156-167.

110. Liu D, Fernandez BO, Hamilton A, et al. UVA irradiation of human skin vasodilates arterial vasculature and lowers blood pressure independently of nitric oxide synthase. J Invest Dermatol. 2014;134(7): 1839-1846.

111. Feelisch M, Kolb-Bachofen V, Liu D, et al. Is sunlight good for our heart? Eur Heart J. 2010;31(9):1041-1045.

112. Rajora N, Ceriani G, Catania A, Star RA, Murphy MT, Lipton JM. Alpha-MSH production, receptors, and influence on neopterin in a human monocyte/macrophage cell line. J Leukoc Biol. 1996;59(2): $248-253$.

113. Luger TA, Scholzen T, Grabbe S. The role of alpha-melanocytestimulating hormone in cutaneous biology. J Investig Dermatol Symp Proc. 1997;2(1):87-93.

114. Hogman M. Extended NO analysis in health and disease. $J$ Breath Res. 2012;(4):047103. 
115. Bhowmik A, Seemungal TA, Donaldson GC, Wedzicha JA. Effects of exacerbations and seasonality on exhaled nitric oxide in COPD. Eur Respir J. 2005;26(6):1009-1015.

116. Sethi S, Evans N, Grant BJ, MurphyTF. New strains of bacteria and exacerbations of chronic obstructive pulmonary disease. $N$ Engl $J$ Med. 2002;347(7):465-471.

117. Sethi S, Murphy TF. Infection in the pathogenesis and course of chronic obstructive pulmonary disease. N Engl J Med. 2008;359(22): 2355-2365.

118. Seemungal T, Harper-Owen R, Bhowmik A, et al. Respiratory viruses, symptoms, and inflammatory markers in acute exacerbations and stable chronic obstructive pulmonary disease. Am J Respir Crit Care Med. 2001;164(9):1618-1623.

119. Wilkinson TM, Hurst JR, Perera WR, Wilks M, Donaldson GC, Wedzicha A. Effect of interactions between lower airway bacterial and rhinoviral infection in exacerbations of COPD. Chest. 2006; 129(2):317-324.

120. Sapey E, Stockley RA. COPD exacerbations. 2: aetiology. Thorax. 2006;61(3):250-258.

121. Yang W, Elankumaran S, Marr LC. Relationship between humidity and influenza A viability in droplets and implications for influenza's seasonality. PLoS One. 2012;7(10):e46789.

122. Lytle CD, Sagripanti JL. Predicted inactivation of viruses of relevance to biodefense by solar radiation. J Virol. 2005;79(22):14244-14252.

123. Feng L, Shay DK, Jiang Y, et al. Influenza-associated mortality in temperate and subtropical Chinese cities, 2003-2008. Bull World Health Organ. 2012;90(4):279B-288B.
124. Eccles R. Acute cooling of the body surface and the common cold. Rhinology. 2002;40(3):109-114.

125. Eccles R. An explanation for the seasonality of acute upper respiratory tract viral infections. Acta Otolaryngol. 2002;122(2):183-191.

126. Salah B, Dinh Xuan AT, Fouilladieu JL, Lockhart A, Regnard J. Nasal mucociliary transport in healthy subjects is slower when breathing dry air. Eur Respir J. 1988;1(9):852-855.

127. Papi A, Bellettato CM, Braccioni F, et al. Infections and airway inflammation in chronic obstructive pulmonary disease severe exacerbations. Am J Respir Crit Care Med. 2006;173(10):1114-1121.

128. England $P H$. Surveillance of influenza and other respiratory viruses in the United Kingdom: Winter 2015 to 2016; 2016:1-44. Available from: https://assets.publishing.service.gov.uk/government/ uploads/system/uploads/attachment_data/file/526405/Flu_Annual_ Report_2015_2016.pdf. Accessed March 3, 2018.

129. Makinen TM, Juvonen R, Jokelainen J, et al. Cold temperature and low humidity are associated with increased occurrence of respiratory tract infections. Respir Med. 2009;103(3):456-462.

130. Johnson C, Eccles R. Acute cooling of the feet and the onset of common cold symptoms. Fam Pract. 2005;22(6):608-613.

131. Ikaheimo TM, Jaakkola K, Jokelainen J, et al. A decrease in temperature and humidity precedes human rhinovirus infections in a cold climate. Viruses. 2016;8(9):E244.

132. Donaldson GC, Keatinge WR. Mortality related to cold weather in elderly people in southeast England, 1979-94. BMJ. 1997;315(7115): 1055-1056.
International Journal of COPD

\section{Publish your work in this journal}

The International Journal of COPD is an international, peer-reviewed journal of therapeutics and pharmacology focusing on concise rapid reporting of clinical studies and reviews in COPD. Special focus is given to the pathophysiological processes underlying the disease, intervention programs, patient focused education, and self management protocols.

\section{Dovepress}

This journal is indexed on PubMed Central, MedLine and CAS. The manuscript management system is completely online and includes a very quick and fair peer-review system, which is all easy to use. Visit http://www.dovepress.com/testimonials.php to read real quotes from published authors. 